\title{
Editorial
}

\section{Perspectives on Higher Education in North America}

\section{Introduction}

This issue of Higher Education Policy, the first brought out under the imprimatur of Palgrave Academic, focuses on certain key topics that are currently shaping higher education in the United States and Canada. To concentrate on a particular geographical area as opposed to a specific theme is not the usual approach of this journal. However, ringing the changes is never a bad thing and excellent and persuasive reasons may be invoked in justification for it. Prime among these reasons is, of course, that the specific area to which this journal is devoted, namely the analysis of higher education policy, developments in North America represent a bell weather. A second, although it may command less consensus, is the basic fact that the United States enjoys a very special position and has done so for a considerable time as one of, if not 'the' major 'referential system' in higher education and very especially so since the fall of the Berlin Wall and the rapid disappearance of the one-time 'Soviet' model of higher education.

To be sure, the United States is not alone in the enjoyment of this standing. At different times, other systems have exercised a similar function. One thinks here, for instance, of the Spanish model of university, the first to be exported beyond the confines of Europe in the course of the 16th and 17th centuries; the British or, as Trow's exploration of the changes in relationship between government and higher education in the United States of the early 19th century shows us, the University of Cambridge in the 17th century. Naturally, the list may be extended to include the French and German referential models. The former shaped the provision of higher learning in Latin America of the late 19th century. The latter provided the prototype of what contemporary jargon hails as 'the research university', a term many look upon with distaste as a blatant redundancy. 
2

\section{Forces Underlying the Rise of a System to 'Referential Status'}

If certain systems of higher education have served at varying stages of their fortunes as models, templates or have provided both the organizational forms and pedagogic practices upon which others have chosen to ground their own system of higher education, we are faced with a rather basic question. That question is surely, 'What are the forces that propel a given system of higher education towards referential status?' There are, of course, obvious answers: transportation by emigrants and implantation of established institutional patterns and provision as part of creating a colonial society; development of new and innovative ways of organizing and transmitting knowledge; and, more recently and very particularly since the latter part of the 1950s, outstanding economic success. Indeed, one feature, which increasingly bears down upon the university, redefining its purpose and its mission, lies precisely in playing up its symbolic value as a surrogate statement of the economic health or malaise of the country responsible for maintaining it. Although this interpretation reaches its height under the impetus of contemporary neo-liberalism, it has been explicit from the moment when, in advanced economies beyond the United States, higher education moved forward towards acquiring mass status. This stage was reached in Western Europe in the course of the 1970s, that is, some three decades after it had been attained in the United States. That the United States was the pioneer in this feat went far in urging it along the path towards 'referential status ${ }^{1}$ and very particularly so as other national systems began to move along the same developmental path.

\section{The Case of the USA}

That the USA stands as a pole of reference today in no way changes the fact that its historical development took it down very different paths from, say, its European counterparts. These are traced by Martin Trow in the opening article, which sets the origins and the driving forces behind American higher education across the past two centuries. Of special interest is his citing the concept of the market as one of the fundamental social institutions of early American society. As he points out, the notion of market had major implications for the relationship between government and university as did the absence of a powerful civil service. Thus, from the turn of the 19th century onwards, the market acted as a powerful definitional force in determining both who should provide higher education and to what end. And, no less important, the market laid down the contextual limits to a mental set that not only constitutes the central ethos of higher education in the USA but one that, despite the move towards nominally similar structures the European concept of the Bachelors degree ushered in by the Bologna process is a particularly 
striking illustration in the world of contemporary higher education policy is not always grasped in its full implications by those who observe the development of higher education in the USA from the outside.

\section{Key Decade}

If one cares to look at it in such terms, the decade and a half from 1806 through to 1819 was one of the most important in laying down the basic framework from which three referential models were later to emerge: the French reforms associated with the Napoleonic University, which took place between 1806 and 1808, the establishment of the University of Berlin in 1810 and the Dartmouth judgment of 1819. In the case of the first two, reform tied the university to the modernization of national bureaucracy and to the mission of upholding national coherence. The latter, as Trow notes, saw the defeat of precisely this model and in place of a service state protected and state provided, saw the emergence of a service offered by individual initiative and owned by a corporation of founders to the nation. If the first construed higher education in terms of the public good and the general interest, the second emphasized private benefit and individual advance, issues that, are today once again to the fore in negotiating the place of education in general and higher education very especially so, in the general agreement on Trade and Tariffs on Services.

While Trow takes us into the founding values of higher education in the early days of the Republic, Zamani and Brown look at the interplay between meritocracy and access, an issue that, in the United States, has acquired a solid ethnic dimension in place of the social class overtones that once prevailed and that still tend to prevail in Europe. However, here too some might care to argue that this is beginning to change even in Europe as the sons and daughters from second-generation immigrant families are now reaching the gates of academe.

\section{Making Sense of 'Sensemaking'}

Eckel and Kazar examine an issue which, if, at present, appears in the first stages of exploration in the United States, is likely to have similar relevance elsewhere, namely the pace of change and how to 'root' it in the 'mentality' of those affected parties and constituencies in academia. They broach a delicate topic, and one that stands very much as a new perspective on a well-honed problem, namely the social acceptability of change, this time focused upon the academic estate as its recipient. Change, however, cannot entirely be reduced to re-engineering the 'attitudes' of those affected. Nor can it wholly be reduced to the abstractions of a 'mental set', for mental sets are more often than not generated by self-interest or the individual's perception of the same. And 
attitudes are not entirely independent of material conditions. Making positive sense of changing conditions of academic work may certainly be one way of ensuring a certain acquiescence.

\section{The Noble Art of Lobbying}

Ferrin's contribution provides a fascinating glimpse into an activity at the interface between higher education and government to which all too little attention is paid. Lobbying is, of course, very far from being exclusive to the universities of North America. And no University President, Rector or Vice Chancellor would even bother to deny it, for much of his or her work is taken up with precisely this. However, as with so much of higher education in the USA when viewed from an outsider's perspective, what is different is not the activity itself so much as its formal organization and recognition, whereas in other systems it remains disguised, hidden as something that 'dares not say its name'. Yet, lobbying or whatever the happy euphemism one cares to employ is the natural outcome of competition for resources. It is also the product of the lamentable shrinkage in that part of the institutional budget, which the Prince once provided and on which Rectors could once count or squabble over with the appropriate ministry.

This does not mean to say that competition and diversification of funding are the father and mother of lobbying. But most assuredly, they serve to amplify it. They turn what was once the quest for marginal advantage into a matter of survival and most certainly of repute. Lobbying under such conditions becomes an organizational response to competition and diversity.

Arguably, lobbying accelerates further when national systems are drawn increasingly to compete for the manna and quails that supranational or intergovernmental agencies hold forth. Thus, one outcome of creating both a higher education area in Europe of the 15, and a european research area will almost certainly be to bring the 'noble art' of lobbying from the shadows, if it has not already done so. Ferrin's article gives us much to muse upon but nearer to home.

\section{Ranking, Productivity and 'Steering by Public Status'}

There are, however, other dimensions at stake in the activity of lobbying, apart from the securing of resources, the forwarding of interests and the protection of repute. One of the most significant of these is what might be termed 'steering by public status', which itself is one of the major consequences of higher education driven by market forces rather than social demand. In effect, the demand for information about the perceived standing and repute of individual 
universities is a key element in giving the individual the means of making a rational choice of establishment or department. In this domain, the creation of League Tables of Performance, the rise of indicators of productivity may be seen as part of that process which involves transferring knowledge, once 'private' in the sense of being possessed within the academic community, into the public domain. Such rating systems have long been a feature of the higher education landscape in the United States. Elsewhere, in Europe for instance, they are more recent and are largely the work of the past decade and a half, a development often presented in terms of the rise of the evaluative state.

Such procedures of productivity assessment are immensely powerful, and very especially so when linked to the allocation of resources, within the individual university as they are between them. Agreed, not all governments or legislatures have tied the two together, although the trend in the United States lies increasingly in that direction. 'Steering by public status' or, to put matters slightly differently, 'by status publicly assigned' is, however, not always as transparent as its proponents would wish. There are different levels of aggregation and disaggregation, from the performance of individual disciplines and subjects, through to faculties and on to the university in toto. Furthermore, there are also issues of high technicity, which often turn about the methodology involved, quite apart from their interpretation. And, last but not least, the interpretations placed upon them by those with 'inner knowledge' do not always accord with the interpretation laid upon those same results by those who bring the results before the public. A particularly good illustration of the very real difficulties involved is provided by Maton and his colleagues with the field of psychology.

\section{Higher Education, Jobs and the Enlightenment of the Citizen}

Lin, Sweet and Anisef turn our attention to a different but no less pervasive issue, namely the tension between liberal education and vocational training in the choice of students of what they will study. Outwardly, this is a North American issue par excellence. Formally speaking, the equivalent of liberal education - culture generale, Allgemeinbildung or the rarer Academische Voorming, respectively its counterpart in France, Germany and the Netherlands - is primarily a matter for secondary schooling (for a recent debate on this, see Higher Education Policy vol. 15, No. 1 March 2002 General Education: new rationales, new thinking).

Still, the issue that Lin, Sweet and Anisef anaylse in a Canadian setting is very far from being simply another example of North American exceptionalism. It is, perhaps, not greatly surprising that at the very moment when, at all levels - local, regional and national - the traditional concept of community is 
6

dissolving before the drive to reduce social units to atomistic and coincidental groupings of consumers, clients and markets, that the particular form of socialization which the liberal interpretation of education entails should dissolve with it. The drive of Canadian students towards the vocational dimension, whatever the reasons, and Lin, Sweet and Anisef explore them in considerable detail, would appear to reflect very faithfully the increasing attention that higher education is obliged to pay to the short term, to the honing of techniques and skills and to the socialization into an anticipated occupation.

Seen from this angle, developments in Canada find a ready echo in other systems of higher education among the so-called 'knowledge economies'. The paradox emerges, of course, once one sets the vocational imperative, that is training and socialization, into future occupational practices against that other fundamental feature of the knowledge economy - to wit, the ephemeral nature of the very occupations to which such training leads an in-built precariousness that higher education is called upon to attenuate and to remedy by summoning up the virtues of 'flexibility' and lifelong learning. From there to asking whether higher education is not increasingly engaged in the training of workers, obedient in thought and gesture to the task others set, rather than committed to the education of responsible citizens, prepared to uphold the interests of the social as opposed to the productive - or consuming community, is but a short step.

\section{Institutional Funding}

Finally, Edisooriya takes us into the realm of institutional funding. $\mathrm{He}$ highlights a dilemma which, if especially acute in Tennessee, would appear to be generic to higher education systems where public policy also carries with it the notion of 'rolling back the frontiers of the state'. It is a classic dilemma. 'Can the Prince demand quality if he is reluctant to back his demand with the means of upholding it?' The pragmatic answer is, of course, 'He can indeed'. If one casts one's net a little further afield and pushes one's trawl rather deeper into the waters of time, one has to admit that very few indeed are the systems of higher education where, over the course of the past 15 years or so, the Prince has not done precisely that. Tennessee is then in a company both numerous and excellent.

Whether the formula Edisooriya proposes may find application elsewhere is, however, a different matter. That said, his contribution poses a number of interesting questions, not least of which is the belief, commonly held, that 'heavy dependence on state support is (our italics) detrimental to operational viability'. To this, there is always the counterpoint. And that counterpoint is, 
surely, whether a similar degree of dependence on private support would not prove just as detrimental? In effect, while shifts in funding almost always pose the question of the degree of dependence involved, the question of its provenance is largely irrelevant. If one sups with the devil, it is always best to bring a long spoon. And independence is largely a matter of how many devils one is prepared to dine with rather than their fiendish nature or intent, although it is wise to bear both in mind when ordering the wine!

\section{To our Readers}

Readers cannot fail to have noticed the changes in the appearance of the new cover, new size, new layout and new presentation features of Higher Education Policy, designed to delight the eye and tickle the fancy. They also mark the transfer of Higher Education Policy to Palgrave Macmillan. There were many reasons for this decision, not least because Palgrave Macmillan already publishes the major reference works of the International Association of Universities including the International Handbook of Universities and the World Academic Database. In future, Palgrave Macmillan will also be publishing the Association's comparative higher education policy series Issues in Higher Education. Change, however, is balanced by judicious and necessary continuity. The range and quality of Higher Education Policy will remain as ever they have been these 15 years past. We hope both will be equally pleasing to our readers.

However, presentation is not the only innovation that comes from our new agreement with Palgrave Macmillan. Thanks to Palgrave Macmillan's generosity and inventiveness, the International Association of Universities has decided to create an 'IAU Prize Essay in Higher Education Policy'. Sponsored by Palgrave Macmillan, this award will be for the most outstanding essay on a topic to be determined annually and announced in this journal as well as on the IAU website. Readers are invited to consult our website for further details and for the subject to be developed: http://www.unesco.org/iau/ The award winner will be announced at the Association's 12th General Conference, which will take place at Sao Paulo (Brazil) in July 2004.

Guy Neave

International Association of Universities

UNESCO House

1 rue Miollis

75732 Paris Cedex 15

France

Higher Education Policy (2003) 16, 1-7. doi:10.1057/palgrave.hep.8300007 